\title{
Early Postnatal Changes in Intracranial Arterial Blood Flow Velocities in Term Infants
}

\author{
SVEN-ERIK SONESSON, PER WINBERG, AND BO P. W. LUNDELL \\ Department of Pediatrics, Karolinska Institute, Karolinska Hospital, St. Göran's and Sachs' Children's \\ Hospitals, Stockholm, Sweden
}

\begin{abstract}
A range-gated Doppler technique was used to assess intracranial arterial blood flow velocity changes in 20 healthy term infants during the first 3 days after birth. Systolic, diastolic, and mean flow velocity decreased during the first $\mathbf{3 0}$ min after birth whereas arterial pressure and heart rate did not change. Mean flow velocity did not change from $30 \mathrm{~min}$ to $72 \mathrm{~h}$ of life, although systolic and diastolic flow velocity changed in opposite directions. Systolic flow velocity increased to $2 \mathrm{~h}$ of age and thereafter decreased. Diastolic flow velocity decreased to a minimum value at $2 \mathrm{~h}$ and thereafter increased to $24 \mathrm{~h}$ of age. These flow velocity changes suggest an initial decrease in cerebral perfusion, followed by a constant cerebral blood flow during normal circulatory transition after birth. (Pediatr Res 22: 461-464, 1987)
\end{abstract}

\section{Abbreviations}

V syst, peak systolic blood flow velocity

$V$ diast, end-diastolic blood flow velocity

$\checkmark$ mean, temporal mean blood flow velocity

Disturbances in the cerebral circulation during or after birth are thought to be a major cause of cerebral hemorrhage and ischemic-hypoxic encephalopathy in the newborn infant. Hence, knowledge about normal cerebrovascular physiology is essential in order to understand the pathogenesis of these disorders and to permit prophylactic measures for infants at risk. Much data have been obtained from animal studies (1-3). However, these findings may not be applicable to newborn infants due to differences in cerebral anatomy and degree of maturation at birth. Several noninvasive techniques have been used to evaluate cerebral blood flow in the newborn infant (4). However, few attempts have been made to investigate normal cerebral circulation during the first days of life (5-8), and the effects of early neonatal cardiorespiratory transition on cerebral circulation have not been investigated. In the present study a range-gated Doppler velocimeter was used to measure changes in intracranial arterial blood flow velocities in healthy term newborn infants during the first hours of normal cardiorespiratory transition, and the following 3 days after birth.

\section{MATERIALS AND METHODS}

Twenty term newborn infants, delivered by cesarean section, were studied. Indications for cesarean section were cephalopelvic

Received February 7, 1987; accepted May 19, 1987.

Correspondence Sven-Erik Sonesson, Department of Paediatrics, Karolinska Hospital, S-104 01 Stockholm, Sweden.

Supported by The Expressen Prenatal Research Foundation, The General Maternity Hospital Foundation, Stiftelsen Samariten, The Laerdal Foundation for Acute Medicine, and the Swedish Society of Medicine. disproportion, breach presentation, or prior cesarean section. Epidural anesthesia by bupivacaine $(n=17)$ or general anesthesia induced by barbiturates $(n=3)$ were used. Parental consent was obtained prior to delivery in all cases, and the study was approved by the local Committee of Ethics.

Hematocrit and $\mathrm{pH}$ were measured in umbilical arterial blood drawn at birth from the double clamped umbilical cord. Intracranial arterial blood flow velocities were measured with a combined continuous and range-gated Doppler instrument (Alfred, Vingmed A/S, Oslo, Norway). The high pass filter, used to remove low frequency noise, i.e. vessel wall movements, was set at the minimum level $(100 \mathrm{~Hz})$. A $2 \mathrm{MHz} 8 \mathrm{~mm}$ diameter handheld transducer was placed on the anterior fontanel and the ultrasound beam was directed toward the internal carotid artery at the base of the skull. Guided by the velocity signal displayed on an oscilloscope and as an audio-signal, the maximum depth with the highest possible velocities were used. In the range-gated mode, the maximum velocity, the space average velocity (the average over the cross-section of the blood vessel), and the temporal mean of the space average velocity (the area under the curve) were recorded on an oscillograph. Signals generated by the Doppler velocimeter were used for calibration of the velocity recordings. The absolute Doppler frequency shifts were used for calculation of velocities. A stable velocity recording over $20-30$ consecutive beats with the highest amplitude recorded was analyzed by hand. V syst, V diast, and V mean were averaged from space average velocity recordings from both sides of the skull (9). Single-sided or shorter recordings were accepted only in the recordings before $15 \mathrm{~min}$ of age, due to the problem of keeping the infant from moving. In these cases blood flow velocities were averaged from several shorter periods of good quality recordings. When necessary, end-diastolic velocities below $3.9 \mathrm{~cm} / \mathrm{s}(15$ of 120 recordings), omitted by the high pass filter, were extrapolated from preceding and following sections of the velocity waveform (Fig. 1). Determinations of systolic and diastolic velocities were also made from the maximum velocity recordings. Heart rate was calculated from the velocity recordings.

Arterial blood pressure was measured noninvasively by cuff on the right upper arm and an oscillometric blood pressure monitor (Omega 1400, In Vivo Research Lab, Inc, Broken Arrow, OK) $(10,11)$. The average of the two measurements made in connection with the Doppler recordings was used.

Recordings of flow velocities and arterial pressure were made in the supine position at six different occasions in all newborns. I at $<15 \mathrm{~min}$, II at $30 \mathrm{~min}$, III at $2 \mathrm{~h}$, IV at $5(4-6) \mathrm{h}, \mathrm{V}$ at 24 $(22-26) \mathrm{h}$, and VI at $72(70-74) \mathrm{h}$ after birth. The newborns were often alert and restless at the first examination and calm and mostly asleep at the following recordings. Recording $\mathrm{V}$ and VI were made $30-60$ min after feeding. Statistical analysis was performed using two-way analysis of variance. Intraindividual comparisons over time were made as orthogonal contrast (I versus II, III versus IV, III and IV versus $\mathrm{V}$ and VI, and V versus VI) (12). These comparisons were based on the assumption that I and II would reflect the early respiratory and hormonal changes 


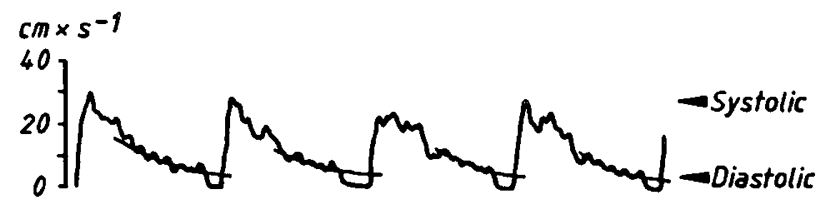

Fig. 1. An intracranial flow velocity recording with loss of enddiastolic signal due to the $100 \mathrm{~Hz}$ high pass filter, and the extrapolation of the end-diastolic flow velocity.

following birth, III to V the following circulatory adaption, and $\mathrm{V}$ to VI later changes in the cerebral circulation.

\section{RESULTS}

All infants were products of uncomplicated cesarean sections and had an apparently normal cardiorespiratory transition. Gestational age and weight at birth were $38.7(0.7) \mathrm{wk}$, mean and 1 $\mathrm{SD}$, and $3173(282) \mathrm{g}$, respectively.

Umbilical artery pH was $7.30(0.04)$ in 19 infants. One infant with a low $\mathrm{pH}$ of 7.12 was also included since we had reason to believe that this value was incorrect. This infant had no signs of distress before or after delivery and did not differ from the other infants in any other respect.

Hematocrit values were 46 (5.9)\%. Heart rate (Fig. 2) did not change significantly between $<15 \mathrm{~min}$ and $30 \mathrm{~min}$, but later there was a decrease from $146(10.7)$ beats/min at $30 \mathrm{~min}$ to 124 (9.2) beats/min at $5 \mathrm{~h}, p<0.01$.

Arterial pressure (Fig. 2) did not change significantly between the first two recordings. Systolic, diastolic, and mean pressure were lowest at $2 \mathrm{~h}$ of age. Between 2 and $72 \mathrm{~h}$ there was an increase in systolic pressure from $64(9.6)$ to $73(7.7) \mathrm{mm} \mathrm{Hg}, p$ $<0.01$, diastolic pressure from $32(6.6)$ to $44(6.3) \mathrm{mm} \mathrm{Hg}, p<$ 0.001 , and mean pressure from 44 (7.3) to $56(6.2) \mathrm{mm} \mathrm{Hg}, p<$ 0.001 .

V syst (Fig. 3) decreased from $33.7(6.7) \mathrm{cm} / \mathrm{s}$ at $<15 \mathrm{~min}$ to $29.3(6.7) \mathrm{cm} / \mathrm{s}$ at $30 \mathrm{~min}, p<0.01$. Subsequently there was an increase in $\mathrm{V}$ syst, to $33.3(5.8) \mathrm{cm} / \mathrm{s}$ at $2 \mathrm{~h}$, followed by a decrease to $28.0(5.1) \mathrm{cm} / \mathrm{s}$ at $72 \mathrm{~h}, p<0.001$. V diast (Fig. 3) decreased from the first recording to $2 \mathrm{~h}$ of age, from 8.8 (4.6) to $4.3(1.9) \mathrm{cm} / \mathrm{s}, p<0.001$. Later $\mathrm{V}$ diast increased to $6.2(2.1)$ $\mathrm{cm} / \mathrm{s}$ at $5 \mathrm{~h}, p<0.05$, and increased further to $8.5(2.9) \mathrm{cm} / \mathrm{s}$ at $24 \mathrm{~h}, p<0.001$. V mean (Fig. 3) decreased from $18.4(5.0) \mathrm{cm} /$ $\mathrm{s}$ at $<15 \mathrm{~min}$, to $14.7(4.0) \mathrm{cm} / \mathrm{s}$ at $30 \mathrm{~min}, p<0.001$, and thereafter remained unchanged to $72 \mathrm{~h}$ of life.

Changes in systolic and diastolic flow velocities calculated from the maximum velocity recording (Table 1) were similar to changes in $\mathrm{V}$ syst and $\mathrm{V}$ diast calculated from the space average velocity recording (Fig. 3).

\section{DISCUSSION}

The range-gated Doppler technique and the analysis of the frequency spectrum across the lumen of the vessel, used in this study, permits a close measure of true flow velocity (13). Animal experiments have demonstrated a close correlation between changes in extracranial carotid blood flow and flow velocities in basal intracranial arteries (14). A good reproducibility with this technique has also been demonstrated in newborn infants (9). The ultrasound beam from a $8-\mathrm{mm}$ crystal will, if properly directed, insonate the entire cross-section of the internal carotid artery. By recording of the highest frequency Doppler signal and analysis of the sequence with the highest velocities, insonation of the entire cross-section was probably accomplished. Since the angle between the ultrasound beam and the direction of flow in the artery under study is small (15), the absolute Doppler frequency shifts can be used. Incomplete insonation or small variations, between examinations, of the angle of insonation, influences $\mathrm{V}$ syst, $\mathrm{V}$ diast, and $\mathrm{V}$ mean similarly and can accordingly not explain the observations made in this study. The high pass filtering of the velocity signal may cause loss of signal at the low

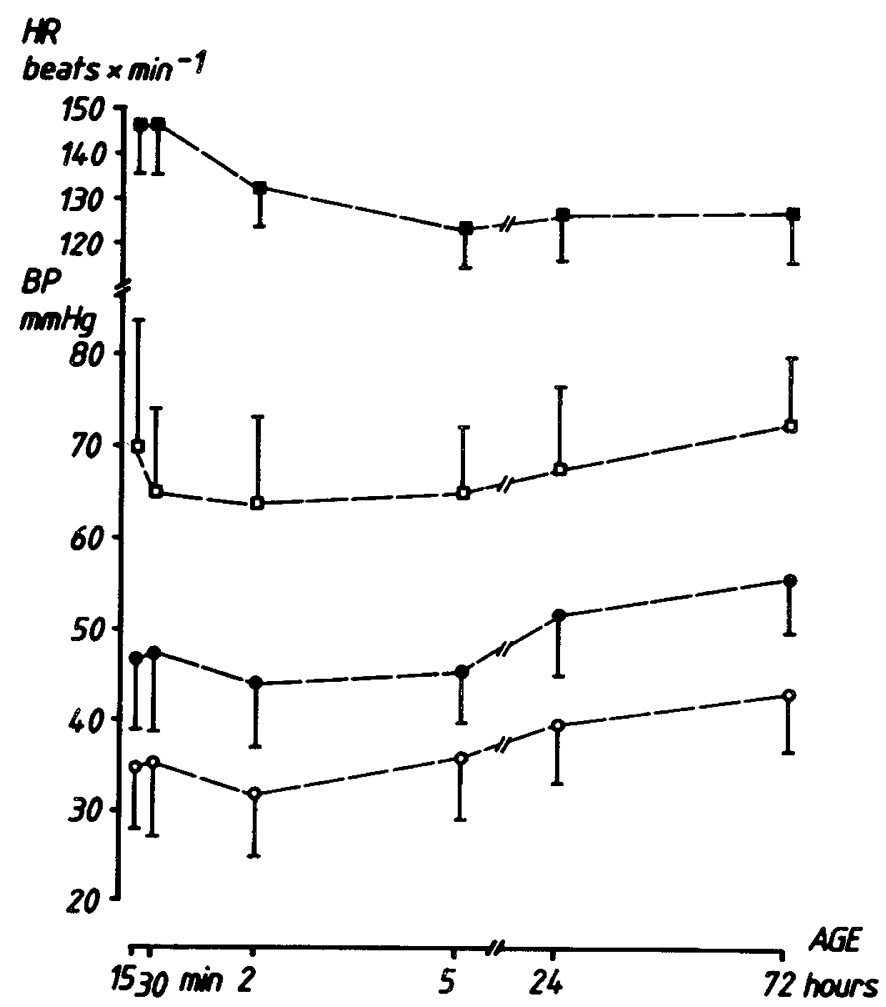

Fig. 2. Heart rate $(H R)$, systolic $(\square)$, diastolic $(O)$, and mean $(\bullet)$ arterial BP during the first 3 days of life (mean and $1 \mathrm{SD}$ ).

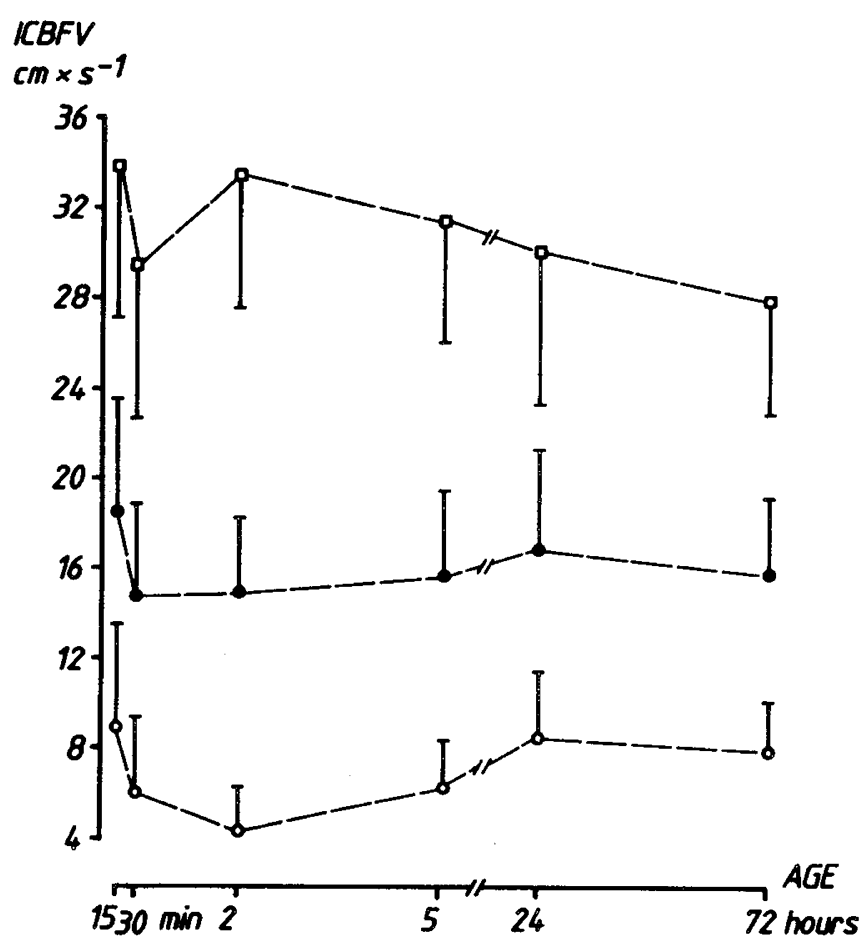

Fig. 3. Systolic $(\square)$, diastolic $(O)$, and mean $(\bullet)$ intracranial arterial blood flow velocities $(I C B F V)$ during the first 3 days of life (mean and $1 \mathrm{SD}$ ).

diastolic velocities found to $5 \mathrm{~h}$ of age. Extrapolation of the signal over a short end-diastolic period (Fig. 1) is, however, considered an appropriate method to obtain a fair estimation of the true end-diastolic velocity. A minor systematic overestimation of the space average velocity may be introduced by the high pass filtering. However, this will not influence the individual changes over time. Although, the maximum velocity might be a less accurate estimate of changes in blood flow compared to the space 
Table 1. Systolic and diastolic intracranial arterial blood flow velocities calculated from maximum velocity recording [mean (1 SD)]

\begin{tabular}{ccccccc}
\hline & $\begin{array}{c}\text { < } 15 \mathrm{~min} \\
(\mathrm{~cm} / \mathrm{s})\end{array}$ & $\begin{array}{c}30 \mathrm{~min} \\
(\mathrm{~cm} / \mathrm{s})\end{array}$ & $\begin{array}{c}2 \mathrm{~h} \\
(\mathrm{~cm} / \mathrm{s})\end{array}$ & $\begin{array}{c}5 \mathrm{~h} \\
(\mathrm{~cm} / \mathrm{s})\end{array}$ & $\begin{array}{c}24 \mathrm{~h} \\
(\mathrm{~cm} / \mathrm{s})\end{array}$ & $\begin{array}{c}72 \mathrm{~h} \\
(\mathrm{~cm} / \mathrm{s})\end{array}$ \\
\hline Systolic & $51.0(9.3)$ & $42.2(6.5)$ & $51.1(7.3)$ & $47.1(6.9)$ & $44.4(9.0)$ & $43.0(6.5)$ \\
Diastolic & $13.2(6.5)$ & $8.8(2.9)$ & $7.7(3.5)$ & $9.1(2.3)$ & $11.8(2.9)$ & $11.7(3.0)$ \\
\hline
\end{tabular}

average velocity $(13,14)$, it has the advantage of being less sensitive to incomplete insonation and the effects from the high pass filter. Yet, changes in maximum and space average velocities were similar (Table 1; Fig. 3). This indicates that variations in insonation, between examinations, and high pass filtering had no measurable effects on our results. By recording from the internal carotid artery we do not measure the contribution of blood flow from the vertebral arteries. It is likely that changes in flow in the vertebral arteries, although not necessarily of the same magnitude, will be in the same direction as in the internal carotid arteries.

Although, the Doppler velocimetric technique will only give information on blood flow velocities and not volume flow, it will correctly identify the direction of changes in cerebral blood flow. Available animal data support this concept that the Doppler technique is useful for studies of qualitative changes in cerebral blood flow (16-18). Thus, in the following discussion, increased blood flow velocities are considered to correspond to increased volume flow, although not necessarily of the same magnitude, and vice versa.

$\mathrm{V}$ syst, $\mathrm{V}$ diast, and $\mathrm{V}$ mean decreased during the first $30 \mathrm{~min}$ after delivery, despite unchanged heart rate and arterial pressure. Assuming unchanged intracranial pressure, a fall in flow velocity and volumetric blood flow without any change in arterial pressure suggests an increase in intracranial vascular resistance in vessels distal to the site of recording. A rise in intracranial pressure may cause similar changes, but is not expected with unchanged central venous pressure (19) and a fall in carbon dioxide tension (20).

An increase in cerebral vascular resistance may be attributed to the fall in carbon dioxide tension at this postnatal age $(2,20)$. However, simultaneous effects from changes in catecholamines (21) and other hormones, vagal activity (1), cerebral activity, and cerebral metabolic rate $(1,22)$ may also be of importance.

The concept of an increasing intracranial vascular resistance during the first 15 to $30 \mathrm{~min}$ of life is supported by other studies. In two studies of newborn lambs with different invasive techniques, high cerebral blood flow values were demonstrated after clamping of the cord, and thereafter cerebral blood flow decreased as ventilation was begun $(1,3)$. This fall in cerebral blood flow was related to a marked increase in vascular resistance (3). In a study of term newborn infants using a venous occlusion plethysmographic technique a $50 \%$ average fall in estimated cerebral blood flow was found during the first $3 \mathrm{~h}$ of life (5).

The following discussion is based on the assumption, supported by another study (23), that intracranial pressure does not change significantly during our study.

Between $30 \mathrm{~min}$ and $2 \mathrm{~h}$ of age $\mathrm{V}$ syst increased, $\mathrm{V}$ diast decreased, but $\mathrm{V}$ mean was unchanged. Heart rate decreased and diastolic and mean arterial pressure tended to fall.

It has been shown that a significant left to right ductus arteriosus shunt reduces the intracranial arterial diastolic flow velocity, probably by means of a ductal steal of systemic blood flow (24). A fall in peripheral vascular resistance may cause the same change, but does not seem to occur during the first $30 \mathrm{~min}$ to 24 $\mathrm{h}$ after birth in term infants delivered by cesarean section (25). Irrespective of the cause of the decrease in V diast, the unchanged $\mathrm{V}$ mean suggests a compensatory fall in intracranial vascular resistance and/or an increase in cardiac output. Increasing V syst without any increase in systolic arterial pressure also suggests a fall in intracranial vascular resistance. However, an increase in left ventricular stroke volume could also contribute to the increase in $\mathrm{V}$ syst at $2 \mathrm{~h}$ of age.
In the 2- to 72-h age period there was no change in $\mathrm{V}$ mean, but $\mathrm{V}$ syst decreased and $\mathrm{V}$ diast increased. Heart rate decreased to $5 \mathrm{~h}$ of age and thereafter stabilized. Diastolic, mean, and to a lesser extent systolic arterial pressure increased.

An explanation for these changes is a diminishing left to right ductal shunt, as suggested by the increase in $\mathrm{V}$ diast and diastolic arterial pressure (24). Furthermore, the unchanged $V$ mean and the decreasing $V$ syst associated with an increase in mean and systolic arterial pressure would favor the concept of an increasing intracranial vascular resistance. However, simultaneous changes in left ventricular stroke volume cannot be ruled out in this study.

Our results suggest an increasing left to right ductus flow during the first postnatal hours and thereafter a decreasing ductal shunt to $24 \mathrm{~h}$ of age. This timing of ductal shunting is in accordance with other studies where quantitative measures of ductus flow have been studied (26).

Two studies, using a continuous wave Doppler velocimeter to measure flow velocities in the anterior cerebral arteries of newborn infants, have demonstrated a decreasing pulsatility index, ( $\mathrm{V}$ syst- $\mathrm{V}$ diast)/V syst, from the 1 st to 2 nd day (6) and between the first 2 and 3-5 days of life (7). The fall in pulsatility index was almost entirely due to an increase in diastolic flow velocity.

Using a more advanced technique in this study, the rangegated Doppler velocimeter and absolute flow velocities, we can confirm previous observations (6-8). We have also more frequently investigated the newborn infants during the first hours of life, and can further interpret the early postnatal changes in intracranial hemodynamics.

The observations in the present study suggest that the newborn term infant, after an early adjustment of cerebral perfusion, maintains a constant cerebral blood flow during the early neonatal circulatory transition.

\section{REFERENCES}

1. Purves MJ, James IM 1969 Observations on the control of cerebral blood flow in the sheep fetus and newborn lamb. Circ Res 25:651-667

2. Barker JN 1966 Fetal and neonatal cerebral blood flow. Am J Physiol 210:897902

3. Lucas W, Kirschbaum T, Assali NS 1966 Cephalic circulation and oxygen consumption before and after birth. Am J Physiol 210:287-292

4. Kirsch JR, Traystman RJ, Rogers MC 1985 Cerebral blood flow measurement techniques in infants and children. Pediatrics 75:887-895

5. Cooke RWI, Rolfe P, Howat P 1979 Apparent cerebral blood flow in newborns with respiratory disease. Dev Med Child Neurol 21:154-160

6. Gray PH, Griffin EA, Drumm JE, Fitzgerald DE, Duignan NH 1983 Continuous wave Doppler ultrasound in evaluation of cerebral blood flow in neonates. Arch Dis Child 58:677-681

7. Archer LNJ, Evans DH, Levene MI 1985 Doppler ultrasound examination of the anterior cerebral arteries of normal newborn infants: The effect of postnatal age. Early Hum Dev 10:255-260

8. Ando Y, Takashima S, Takeshita K 1983 Postnatal changes of cerebral blood flow velocity in normal term neonates. Brain Dev 5:525-528

9. Winberg P, Dahlström A, Lundell B 1986 Reproducibility of intracranial Doppler flow velocimetry. Acta Paediatr Scand [Suppl] 329:134-139

10. Pellegrini-Caliumi G, Agostino R, Nodari S, Maffei G, Moretti C, Bucci G 1982 Evaluation of an oscillometric method and of various cuffs for the measurement of arterial pressure in the neonate. Acta Paediatr Scand 71:791-797

11. Sonesson SE, Broberger U 1987 Arterial blood pressure in the very low birthweight neonate. Evaluation of an automatic oscillometric technique. Acta Paediatr Scand 76:338-341

12. Snedecor GW, Cochran WG 1980 Orthogonal comparisons. In: Statistical Methods. Iowa State, Ames, IA, pp 226-228

13. Lundell BPW, Lindstrom DP, Arnold TG 1984 Neonatal cerebral blood flow velocity. An in vitro validation of the pulsed Doppler technique. Acta Paediatr Scand 73:810-815

14. Lundell BPW, Kennedy KA, Lindstrom DP, Sundell H, Stahlman MT 1986 Intracranial Doppler flow velocimetry compared with extracranial carotid blood flow measurements. Acta Paediatr Scand [Suppl] 329:127-133 
15. Dilenge D, Heon M 1974 The internal carotid artery. In: Newton TH, Potts DG (eds) Radiology of the Skull and Brain. CV Mosby Co., New York, pp $1205-1215$

16. Batton DG, Hellman J, Hernandez MJ, Maisels MJ 1983 Regional cerebral blood flow, cerebral blood velocity, and Pulsatility index in newborn dogs. Pediatr Res 17:908-912

17. Hansen NB, Stonestreet BS, Rosencrantz. TS, Oh W 1983 Validity of Doppler measurements of anterior cerebral artery blood flow velocity: correlation with brain blood flow in piglets. Pediatrics 72:526-531

18. Rosenberg AA, Narayanan V, Jones MD Jr 1985 Comparison of anterior cerebral artery blood flow velocity and cerebral blood flow during hypoxia. Pediatr Res 19:67-70

19. Taylor PM, Egan TJ, Birchard EL, Bright NH, Wolfson JH 1961 Venous hypertension in the newborn infant associated with delayed clamping of the umbilical cord. Acta Paediatr Scand 50:149-159

20. Tunell R, Copher D, Persson B 1974 The pulmonary gas exchange and blood gas changes in connection to birth. In: Stetson JB, Swyer PR (eds) Neonatal
Intensive Care. Warren H Green, Inc, St Louis, MO, pp 89-106

21. Hägnevik K, Faxelius G, Irestedt L, Lagercrantz H, Lundell B, Persson B 1984 Catecholamine surge and metabolic adaptation in the newborn after vaginal delivery and cesarean section. Acta Paediatr Scand 73:602-609

22. Rahilly PM 1980 Effects of sleep stage and feeding on cranial blood flow of the human neonate. Arch Dis Child 55:265-270

23. Robinson RO, Rolfe P, Sutton P 1977 Non-invasive method for measuring intracranial pressure in normal newborn infants. Dev Med Child Neurol 19:305-308

24. Sonesson SE, Lundell BPW, Herin P 1986 Changes in intracranial arterial blood flow velocities during surgical ligation of the patent ductus arteriosus. Acta Paediatr Scand 75:36-42

25. Faxelius G, Lagercrantz H, Yao A 1984 Sympatoadrenal activity and peripheral blood flow after birth. Comparison in infants delivered vaginally and by cesarean section. J Pediatr 105:144-148

26. Moss AJ, Emmanouilides G, Duffie ER 1963 Closure of the ductus arteriosus in the newborn infant. Pediatrics 32:25-30

\section{Announcement}

\section{Transplacental Effects on Fetal Health}

The symposium will be held at the National Institutes of Health, Bethesda, MD on November 5-6, 1987. The purpose of this symposium is to present our current understanding of the mechanisms of action of biologic agents, the effects of disturbed maternal metabolism, and drug and chemical abuse on the developing fetus of humans and animals. Four major topics are: 1) Congenital Viral Infections 2) Congenital Bacterial and Other Infections 3) Metabolic, Drug and Chemical Teratogens 4) Genetic Engineering.

The symposium will be open and free-of-charge, and places will be reserved for at least 100 participants. Invitations will be given on a first-come basis. For further information contact: George Migaki, DVM, Registry of Comparative Pathology, Armed Forces Institute of Pathology, Washington, D.C. 20306-6000, (202)576-2452. 